\title{
The role of spirituality in health care
}

\author{
Christina M. Puchalski, MD, MS
}

$\mathrm{T}$ he technological advances of the past century tended to change the focus of medicine from a caring, serviceoriented model to a technological, cure-oriented model. Technology has led to phenomenal advances in medicine and has given us the ability to prolong life. However, in the past few decades physicians have attempted to balance their care by reclaiming medicine's more spiritual roots, recognizing that until modern times spirituality was often linked with health care. Spiritual or compassionate care involves serving the whole person-the physical, emotional, social, and spiritual. Such service is inherently a spiritual activity. Rachel Naomi Remen, MD, who has developed Commonweal retreats for people with cancer, described it well:

Helping, fixing, and serving represent three different ways of seeing life. When you help, you see life as weak. When you fix, you see life as broken. When you serve, you see life as whole. Fixing and helping may be the work of the ego, and service the work of the soul (1).

Serving patients may involve spending time with them, holding their hands, and talking about what is important to them. Patients value these experiences with their physicians. In this article, I discuss elements of compassionate care, review some research on the role of spirituality in health care, highlight advantages of understanding patients' spirituality, explain ways to practice spiritual care, and summarize some national efforts to incorporate spirituality into medicine.

\section{COMPASSIONATE CARE: HELPING PATIENTS FIND MEANING IN THEIR SUFFERING AND ADDRESSING THEIR SPIRITUALITY}

The word compassion means "to suffer with." Compassionate care calls physicians to walk with people in the midst of their pain, to be partners with patients rather than experts dictating information to them.

Victor Frankl, a psychiatrist who wrote of his experiences in a Nazi concentration camp, wrote: "Man is not destroyed by suffering; he is destroyed by suffering without meaning" (2). One of the challenges physicians face is to help people find meaning and acceptance in the midst of suffering and chronic illness. Medical ethicists have reminded us that religion and spirituality form the basis of meaning and purpose for many people (3). At the same time, while patients struggle with the physical aspects of their disease, they have other pain as well: pain related to mental and spiritual suffering, to an inability to engage the deepest questions of life. Patients may be asking questions such as the following: Why is this happening to me now? What will happen to me after I die? Will my family survive my loss? Will I be missed? Will I be remembered? Is there a God? If so, will he be there for me? Will I have time to finish my life's work? One physician who worked in the pediatric intensive care unit told me about his panic when his patients' parents posed such questions. It is difficult to know what to say; there are no real answers. Nevertheless, people long for their physicians as well as their families and friends to sit with them and support them in their struggle. True healing requires answers to these questions (3). Cure is not possible for many illnesses, but I firmly believe that there is always room for healing. Healing can be experienced as acceptance of illness and peace with one's life. This healing, I believe, is at its core spiritual.

Two examples illustrate ways to deal with questions related to meaning in life. Many studies have shown that people desire to be remembered (4). Some wish to fulfill this desire through their family, and others through their life's accomplishments or impact. One of my patients has had ovarian cancer for $71 / 2$ years. Recently, the cancer metastasized and is no longer as responsive to chemotherapy. She has been involved in lecturing to a class of my medical students for a 2-week period each semester, talking about medical care from a patient's perspective. Now that she is facing the end of her life, she is determined to continue those lectures; she finds purpose in the significant impact they have had on future physicians. Her treatment team was able to work around certain therapeutic protocols to enable her to achieve her dreams and goals. Another patient was dying of breast and ovarian cancer in her early 30s, and she was depressed. Antidepressants weren't helping. Through talking with her, I understood the cause of her suffering: a fear that her 2-year-old daughter would not remember her. I suggested that she keep a journal to leave to her daughter; the hospice nurses videotaped her messages to her children. These activities helped resolve her depression.

Erik Erikson has written about certain developmental tasks that he suggests children, adolescents, and adults need to accom-

From The George Washington Institute for Spirituality and Health (GWish), The George Washington University Medical Center Departments of Medicine and Health Care Sciences, and The George Washington University, Washington, DC. Presented at Baylor University Medical Center on February 28, 2001, as the BaylorCharles A. Sammons Cancer Center Charlotte Johnson Barrett Lectureship.

Corresponding author: Christina M. Puchalski, MD, MS, GWish, 2300 K Street NW, Warwick Building, Room 336, Washington, DC 20037. 
plish as part of the normal developmental and maturing process (5). Spirituality has been recognized by many authors as an integral developmental task for those who are dying $(6,7)$. Unfortunately, people who are dying are often ignored. DNR-do not resuscitate-is often interpreted as "do not round." As these patients deal with issues of transcendence, they need someone to be present with them and support them in this process. We need to advocate for systems of care in which that can happen.

Attending the dying patient is an important experience for physicians as well. In an article entitled "When mortality calls, don't hang up," Sally Leighton wrote: "The physician will do better to be close by to tune in carefully on what may be transpiring spiritually, both in order to comfort the dying and to broaden his or her own understanding of life at its ending" (8). One Baylor nurse I spoke with said that her patients give back $400 \%$ more than she gives them. I have to echo that sentiment. Being in the presence of people who are struggling and are able to transcend suffering and pain and see life in a different way is inspiring for me, and I'm grateful for those experiences.

\section{RESEARCH ON THE ROLE OF SPIRITUALITY IN HEALTH CARE}

The effect of spirituality on health is an area of active research right now. Besides being studied by physicians, it is studied by psychologists and other professionals. The studies tend to fall into 3 major areas: mortality, coping, and recovery.

\section{Mortality}

Some observational studies suggest that people who have regular spiritual practices tend to live longer (9). Another study points to a possible mechanism: interleukin (IL)-6. Increased levels of IL-6 are associated with an increased incidence of disease. A research study involving 1700 older adults showed that those who attended church were half as likely to have elevated levels of IL-6 (10). The authors hypothesized that religious commitment may improve stress control by offering better coping mechanisms, richer social support, and the strength of personal values and worldview.

\section{Coping}

Patients who are spiritual may utilize their beliefs in coping with illness, pain, and life stresses. Some studies indicate that those who are spiritual tend to have a more positive outlook and a better quality of life. For example, patients with advanced cancer who found comfort from their religious and spiritual beliefs were more satisfied with their lives, were happier, and had less pain (11). Spirituality is an essential part of the "existential domain" measured in quality-of-life scores. Positive reports on those measures-a meaningful personal existence, fulfillment of life goals, and a feeling that life to that point had been worthwhilecorrelated with a good quality of life for patients with advanced disease (12).

Some studies have also looked at the role of spirituality regarding pain. One study showed that spiritual well-being was related to the ability to enjoy life even in the midst of symptoms, including pain. This suggests that spirituality may be an important clinical target (13). Results of a pain questionnaire distributed by the American Pain Society to hospitalized patients showed that personal prayer was the most commonly used non- drug method of controlling pain: $76 \%$ of the patients made use of it (14). In this study, prayer as a method of pain management was used more frequently than intravenous pain medication $(66 \%)$, pain injections $(62 \%)$, relaxation $(33 \%)$, touch $(19 \%)$, and massage (9\%). Pain medication is very important and should be used, but it is worthwhile to consider other ways to deal with pain as well.

Spiritual beliefs can help patients cope with disease and face death. When asked what helped them cope with their gynecologic cancer, $93 \%$ of 108 women cited spiritual beliefs. In addition, $75 \%$ of these patients stated that religion had a significant place in their lives, and $49 \%$ said they had become more spiritual after their diagnosis (15). Among $90 \mathrm{HIV}$-positive patients, those who were spiritually active had less fear of death and less guilt (16). A random Gallup poll asked people what concerns they would have if they were dying. Their top issues were finding companionship and spiritual comfort-chosen over such things as advance directives, economic/financial concerns, and social concerns. Those who were surveyed cited several spiritual reassurances that would give them comfort. The most common spiritual reassurances cited were beliefs that they would be in the loving presence of God or a higher power, that death was not the end but a passage, and that they would live on through their children and descendants (17).

Bereavement is one of life's greatest stresses. A study of 145 parents whose children had died of cancer found that $80 \%$ received comfort from their religious beliefs 1 year after their child's death. Those parents had better physiologic and emotional adjustment. In addition, $40 \%$ of those parents reported a strengthening of their own religious commitment over the course of the year prior to their child's death (18).

These findings are not surprising. We hear them repeated in focus groups, in patients' writings and stories: When people are challenged by something like a serious illness or loss, they frequently turn to spiritual values to help them cope with or understand their illness or loss.

\section{Recovery}

Spiritual commitment tends to enhance recovery from illness and surgery. For example, a study of heart transplant patients showed that those who participated in religious activities and said their beliefs were important complied better with follow-up treatment, had improved physical functioning at the 12-month follow-up visit, had higher levels of self-esteem, and had less anxiety and fewer health worries (19). In general, people who don't worry as much tend to have better health outcomes. Maybe spirituality enables people to worry less, to let go and live in the present moment.

Related to spirituality is the power of hope and positive thinking. In 1955, Beecher showed that between $16 \%$ and $60 \%$ of patients - an average of $35 \%$ - benefited from receiving a placebo for pain, cough, drug-induced mood change, headaches, seasickness, or the common cold when told that the placebo was a drug for their condition (20). Now placebos are used only in clinical trials, and even there, generally about $35 \%$ of people respond to them. Study of the "placebo effect" has led to conclusions that our beliefs are powerful and can influence our health outcomes. Herbert Benson, MD, a cardiologist at Harvard School of Medi- 
cine, has renamed the placebo effect "remembered wellness" (21). I see this as an ability to tap into one's inner resources to heal. Benson, myself, and others see the physician-patient relationship as having placebo effect as well-i.e., the relationship itself is an important part of the therapeutic process. Benson suggests that there are 3 components that contribute to the placebo effect of the patient-physician relationship: positive beliefs and expectations on the part of the patients, positive beliefs and expectations on the part of the physician or health care professional, and a good relationship between the 2 parties (21).

Specific spiritual practices have been shown to improve health outcomes. In the 1960s, Benson began research on the effect of spiritual practices on health. Some people who practiced transcendental meditation approached him in the 1960s and asked him to determine if meditation had beneficial health effects. He found that 10 to 20 minutes of meditation twice a day leads to decreased metabolism, decreased heart rate, decreased respiratory rate, and slower brain waves. Further, the practice was beneficial for the treatment of chronic pain, insomnia, anxiety, hostility, depression, premenstrual syndrome, and infertility and was a useful adjunct to treatment for patients with cancer or HIV. He called this "the relaxation response." Benson concluded: "To the extent that any disease is caused or made worse by stress, to that extent evoking the relaxation response is effective therapy" (22).

Different studies suggest that $60 \%$ to $90 \%$ of all patient visits to primary care offices are related to stress. I teach the relaxation response to many of my patients, and I have found it particularly useful for patients with chronic pain, high blood pressure, headaches, and irritable bowel syndrome. It takes only a few minutes to describe the meditation and to practice it with your patient in the office. The patient then needs to practice the technique at home. I usually suggest people follow up with me in the office more frequently initially as they are learning the technique. After a few semimonthly visits, they switch to brief monthly visits, which can then be tapered. Some of my patients follow up with me by phone if coming to my office frequently is difficult.

\section{ADVANTAGES OF BECOMING FAMILIAR WITH PATIENTS' SPIRITUALITY}

Do patients want physicians to address their spirituality? Research studies have also addressed this issue. In the USA Weekend Faith and Health Poll, 65\% felt that it was good for doctors to speak with them about their spiritual beliefs, yet only $10 \%$ said a doctor had had such a conversation with them (23). A study of pulmonary outpatients at the University of Pennsylvania found that $66 \%$ agreed that a physician's inquiry about spiritual beliefs would strengthen their trust in their physician; $94 \%$ of patients for whom spirituality was important wanted their physicians to address their spiritual beliefs and be sensitive to their values framework. Even $50 \%$ of those for whom spirituality was not important felt that doctors should at least inquire about spiritual beliefs in cases of serious illness (24).

From a physician's standpoint, understanding patients' spirituality is quite valuable as well:

- Spirituality may be a dynamic in the patient's understanding of the disease. For example, when I was a resident I saw a 28. year-old woman whose husband had just left her. She found out that her husband had AIDS, and she asked to be tested. When I met with her to tell her that the test result came back positive, I tried to explain that her illness was diagnosed early and that there had been recent advances in the treatment of HIV that were allowing people to live longer with their illness. She kept referring to God and about why God was doing this to her. I recognized that we weren't connecting, so I asked her about her comments. She proceeded to tell me about being raped as a teenager and having an abortion. In her belief system, that was wrong. I remember her exact words: "I have been waiting for the punishment, and this is it." She did not want to discuss treatment or preventive care such as immunization. I encouraged her to see a chaplain, which she did regularly. In the meantime, I kept seeing her, and I talked with her about her issues of guilt and punishment as well as some education about HIV. But it was not until 1 year later that she was willing to seek treatment. She needed time to work out her own issues of guilt before being able to accept her illness and deal with it. Now, she tells me that had I not addressed her spiritual issues in that first visit, she would never have returned to see me or any other physician. In many patients' lives, spiritual or religious beliefs may affect the decisions they make about their health and illness and the treatment choices they make. It is critical that we as physicians and health care providers listen to all aspects of our patients' lives that can affect their decision making and their coping skills.

- Religious convictions may affect health care decision making. Jehovah's Witness patients rejecting blood transfusions is a classic example, but there are also beliefs around use of ventilators and feeding tubes. One of my patients was an 88-yearold man dying of pancreatic cancer in the intensive care unit. He was on a ventilator. When the treatment team approached his family about withdrawing support, at first they refused, saying that their father was in God's hands and keeping him on support might make a miracle possible. After an ethics consult and a consult with a chaplain, the family had the chance to reframe their own thinking. Eventually, they saw that a peaceful death and their father's union with God could be the miracle. The critical elements in helping the family deal with the situation were the medical team's respecting and not ridiculing the family's beliefs and the chaplain's skill in counseling and helping the family reconcile their religious beliefs with the reality of their father's dying.

- Spirituality may be a patient need and may be important in patient coping. This was true of a patient of mine who died 2 weeks ago. She used her religious beliefs and practices to help her live with serious chronic illness. Many of the 1500 people at her funeral commented on her deep faith and how her spirituality helped her cope with her multiple strokes and diabetes. Towards the end of her life, she was in a coma. Her family asked me to join them in their prayer around their mother's bedside. During the prayer, the family was able to express both their hope in her recovery, but also their request to God for strength to deal with her death if that was to be the outcome. So, for both my patient and my patient's family, spiritual beliefs and practices were the main resource they used to cope with suffering and loss. And this patient and her 
family wanted me, their physician, to be aware of these beliefs and to be open to hearing their spiritual expressions in the clinical setting. Patients may want to discuss their spirituality with their physician, to use their church group as a social support, or to join faith-based organizations for support and guidance.

- An understanding of the patient's spirituality is integral to whole patient care. One of my patients, a 42-year-old woman with irritable bowel syndrome, had several signs of depression, including insomnia, excessive worrying, decreased appetite, and anhedonia. Overall, she felt she had no meaning and purpose in life. She did not respond to medication and diet changes alone. I taught this patient the relaxation response as an adjunct to the medical treatment and counseling she received. She improved when meditation and counseling were added to the treatment regimen.

As shown in the first example of the woman who was HIV positive, some spiritual stances can lead to negative coping: more depression, poorer quality of life, and callousness towards others. This is seen when patients view a crisis as a punishment from God, have excessive guilt, or have absolute belief in prayer and a cure and then can't resolve their anger when the cure does not occur. Generally, however, spirituality leads to positive coping. Patients seek control through a partnership with God, ask God's forgiveness and try to forgive others, draw strength and comfort from their spiritual beliefs, and find support from a spiritual or religious community. These actions lead to less psychological distress (25).

\section{ASPECTS OF SPIRITUAL CARE}

What is involved in serving patients and providing compassionate care? Physicians can begin with the following:

- Practicing compassionate presence-i.e., being fully present and attentive to their patients and being supportive to them in all of their suffering: physical, emotional, and spiritual

- Listening to patients' fears, hopes, pain, and dreams

- Obtaining a spiritual history

- Being attentive to all dimensions of patients and their families: body, mind, and spirit

- Incorporating spiritual practices as appropriate

- Involving chaplains as members of the interdisciplinary health care team

Throughout these activities, it is important to understand professional boundaries. In-depth spiritual counseling should occur under the direction of chaplains and other spiritual leaders, as they are the experts. The physician should not initiate prayer with patients, as this blurs the boundary of physician and clergy. Leading prayer involves specific skills and training that physicians do not have. Furthermore, a physician leading a prayer might lead a prayer from his or her tradition, which could be offensive or inappropriate for the patient. If the patient requests prayer, the physician can stand by in silence as the patient prays in his or her tradition or can contact the chaplain to lead a prayer. Finally, the spiritual history is patient centered, and proselytizing and ridiculing patients' beliefs are not acceptable.

It is important to recognize that patients come to physicians to seek care for their medical condition. In delivering this care, physicians can be respectful and understand the spiritual dimen-
Table 1. The FICA method of taking a spiritual history

F Faith and belief. Ask: Are there spiritual beliefs that help you cope with stress or difficult times? What gives your life meaning?

I Importance and influence. Ask: Is spirituality important in your life? What influence does it have on how you take care of yourself? Are there any particular decisions regarding your health that might be affected by these beliefs?

C Community. Ask: Are you part of a spiritual or religious community?

A Address/action. Think about what you as the health care provider need to do with the information the patient shared-e.g., refer to a chaplain, meditation or yoga classes, or another spiritual resource. It helps to talk with the chaplain in your hospital to familiarize yourself with available resources.

Copyright @ Christina M. Puchalski, MD, 1996.

sion in patients' lives. But to go beyond that, e.g., to lead prayer or provide in-depth spiritual counseling, is inappropriate. Physicians are in a position of power with patients. Most patients come to us in vulnerable times. If the physician suggests a certain religion/spiritual belief or ridicules a patient's belief, the patient might adopt that physician's belief or lack of belief out of fear of disagreeing with a perceived authority. Therefore, it is critical that when discussing spiritual issues with patients, the physician listens and supports and does not guide or lead.

Many physicians are not familiar with spiritual histories. I've developed the "FICA" questions to guide the conversation (Table 1). I teach medical students and physicians to take a spiritual history as part of a social history, at each annual exam, and at follow-up visits as appropriate. A spiritual history helps physicians recognize when cases need to be referred to chaplains. It opens the door to conversation about values and beliefs, uncovers coping mechanisms and support systems, reveals positive and negative spiritual coping, and provides an opportunity for compassionate care.

\section{NATIONAL RECOGNITION OF THE VALUE OF SPIRITUAL CARE}

Several prominent organizations have recognized the importance of spiritual care. The Joint Commission on Accreditation of Healthcare Organizations has a policy that states: "For many patients, pastoral care and other spiritual services are an integral part of health care and daily life. The hospital is able to provide for pastoral care and other spiritual services for patients who request them" (26).

The American College of Physicians convened an end-oflife consensus panel that concluded that physicians should extend their care for those with serious medical illness by attention to psychosocial, existential, or spiritual suffering (27). In addition, the Association of American Medical Colleges (AAMC) has embarked on a study of medical education. It convened a consensus group of deans and faculty of medical schools to determine the key elements of a medical school curriculum. In its first report, it listed the essential attributes of physicians. The first attribute is that physicians should be altruistic: "Physicians must be compassionate and empathic in caring for patients. ... In all of their interactions with patients, they must seek to understand the meaning of the patients' stories in the context of the patients' 
beliefs and family and cultural values. ... They must continue to care for dying patients even when disease-specific therapy is no longer available or desired" (28).

In 1992, 3 medical schools offered courses on spirituality and health. In 2001, 75 of the 125 schools offer courses. Many of those courses are required. At The George Washington University School of Medicine, spirituality is interwoven with the rest of the curriculum throughout the 4 years of medical school so that the students learn to integrate it into all of their care. Most of the other schools follow this model of integrating spirituality into ongoing parts of the medical school curriculum. The reason for this is that it is a good model for teaching principles of care. Since the goal of good medical care is attention to the whole patient, not just the specific illness, courses that are taught holistically, rather than by symptoms only, emphasize whole patient care. So, when learning about a patient with diabetes, students learn not only about the pathophysiology of diabetes but also about the psychosocial and spiritual issues that patients with diabetes may face. Thus, when learning to take a history, students learn all aspects of the history-physical, social, emotional, and spiritual.

The John Templeton Foundation supports the development of curricula on spirituality and medicine in medical schools and in residency training programs. The grant program has been successful: not only do the schools and programs continue the curricula after the funding ends, but even schools that have applied and not received funding continue to offer the course. One of the requirements to apply for the award is to have approval from the dean and necessary education committees to offer the course. Once this is done, many schools elect to offer the course even if funding is not awarded. This suggests that medical school faculty find the topic of spirituality and health relevant to medical education and patient care.

The AAMC has also addressed the curriculum in spirituality, cultural issues, and end-of-life care. In its third report, the association outlined outcome goals and learning objectives for spirituality (Table 2). First, the consensus group noted that we are coming to understand health as a process by which individuals maintain their sense of coherence and meaning in life in the face of changes in themselves such as illness (29). So, spirituality can be seen as that part of people that sees coherence, meaning, and purpose in their lives. The AAMC's definition of spirituality is a broad one:

Spirituality is recognized as a factor that contributes to health in many persons. The concept of spirituality is found in all cultures and societies. It is expressed in an individual's search for ultimate meaning through participation in religion and/or belief in God, family, naturalism, rationalism, humanism, and the arts. All of these factors can influence how patients and health care professionals perceive health and illness and how they interact with one another (30).

Furthermore, the consensus group of faculty that developed the definition also developed guidelines and learning objectives for teaching these courses. One of the basic premises of these courses is that focusing on the spiritual aspect of patients enables one to deliver more compassionate care.

In summary, spirituality can be an important element in the way patients face chronic illness, suffering, and loss. Physicians need to address and be attentive to all suffering of their pa-

\section{Table 2. Recommendations of the Association of American Medical Colleges for a Curriculum on Spirituality*}

\section{Outcome goals}

Students will be aware that spirituality, and cultural beliefs and practices, are important elements of the health and well-being of many patients. They will be aware of the need to incorporate awareness of spirituality, and culture beliefs and practices, into the care of patients in a variety of clinical contexts. They will recognize that their own spirituality, and cultural beliefs and practices, might affect the ways they relate to, and provide care to, patients.

Students will be aware of the range of end-of-life care issues and when such issues have or should become a focus for the patient, the patient's family, and members of the health care team involved in the care of the patient. They will be aware of the need to respond not only to the physical needs that occur at the end of life, but also the emotional, sociocultural, and spiritual needs that occur.

\section{Learning Objectives}

With regard to spirituality and cultural issues, before graduation students will have demonstrated to the satisfaction of the faculty:

- The ability to elicit a spiritual history

- An understanding that the spiritual dimension of people's lives is an avenue for compassionate caregiving

- The ability to apply the understanding of a patient's spirituality and cultural beliefs and behaviors to appropriate clinical contexts (e.g., in prevention, case formulation, treatment planning, challenging clinical situations)

- Knowledge of research data on the impact of spirituality on health and on health care outcomes, and on the impact of patients' cultural identity, beliefs, and practices on their health, access to and interactions with health care providers, and health outcomes

- An understanding of, and respect for, the role of clergy and other spiritual leaders, and culturally based healers and care providers, and how to communicate and/or collaborate with them on behalf of patients' physical and/or spiritual needs

- An understanding of their own spirituality and how it can be nurtured as part of their professional growth, promotion of their well-being, and the basis of their calling as a physician

*From reference 30 .

tients-physical, emotional, and spiritual. Doing so is part of delivery of compassionate care. I think we can be better physicians and true partners in our patients' living and in their dying if we can be compassionate: if we truly listen to their hopes, their fears, and their beliefs and incorporate these beliefs into their therapeutic plans.

1. Remen RN. Kitchen Table Wisdom: Stories That Heal. New York: Riverhead Books, 1997.

2. Frankl VE. Man's Search for Meaning. New York: Simon and Schuster, 1984

3. Foglio JP, Brody H. Religion, faith, and family medicine. J Fam Pract 1988; 27:473-474.

4. VandeCreek L, Nye C. Trying to live forever: correlates to the belief in life after death. Journal of Pastoral Care 1994;48(3).

5. Erikson E. Childhood in Society. New York: Norton, 1950.

6. Derrickson BS. The spiritual work of the dying: a framework and case studies. Hosp J 1996;11:11-30.

7. Moberg D. Spiritual well-being of the dying. In Lesnoff-Caravaglia G, ed. Aging and the Human Condition. New York: Human Science Press, 1982. 
8. Leighton S. When mortality calls, don't hang up. Spiritual Life 1996; 22(3):150-157.

9. Strawbridge WJ, Cohen RD, Shema SJ, Kaplan GA. Frequent attendance at religious services and mortality over 28 years. Am J Public Health 1997; 87:957-961.

10. Koenig HG, Cohen HJ, George LK, Hays JC, Larson DB, Blazer DG. Attendance at religious services, interleukin-6, and other biological parameters of immune function in older adults. Int J Psychiatry Med 1997; 27:233-250.

11. Yates JW, Chalmer BJ, St James P, Follansbee M, McKegney FP. Religion in patients with advanced cancer. Med Pediatr Oncol 1981;9:121-128.

12. Cohen SR, Mount BM, Strobel MG, Bui F. The McGill Quality of Life Questionnaire: a measure of quality of life appropriate for people with advanced disease. A preliminary study of validity and acceptability. Palliat Med 1995;9:207-219.

13. Brady MJ, Peterman AH, Fitchett G, Mo M, Cella D. A case for including spirituality in quality of life measurement in oncology. Psychooncology 1999; 8:417-428.

14. McNeill JA, Sherwood GD, Starck PL, Thompson CJ. Assessing clinical outcomes: patient satisfaction with pain management. J Pain Symptom Manage 1998;16:29-40.

15. Roberts JA, Brown D, Elkins T, Larson DB. Factors influencing views of patients with gynecologic cancer about end-of-life decisions. Am J Obstet Gynecol 1997;176(1 Pt 1):166-172.

16. Kaldjian LC, Jekel JF, Friedland G. End-of-life decisions in HIV-positive patients: the role of spiritual beliefs. AIDS 1998;12:103-107.

17. George H. Spiritual Beliefs and the Dying Process: A Report on a National Survey. Conducted by Gallup International Institute for the Nathan Cummings Foundation and the Fetzer Institute, 1997. Available at http://www.ncf.org/ reports/rpt_fetzer_contents.html (accessed July 2001).

18. Cook JA, Wimberly DW. If I should die before I wake: religious commitment and adjustment to death of a child. Journal of the Scientific Study of Religion 1983;22:222-238.
19. Harris RC, Dew MA, Lee A, Amaya M, Buches L, Reetz D, Coleman C. The role of religion in heart-transplant recipients' long-term health and well-being. Journal of Religion and Health 1995;34(1):17-32.

20. Beecher HK. The powerful placebo. JAMA 1955;159:1602-1606.

21. Benson H. Timeless Healing: The Power and Biology of Belief. New York: Simon and Schuster, 1996.

22. Benson H. The Relaxation Response, reissue ed. New York: Avon, 1990.

23. McNichol T. The new faith in medicine. USA Today Weekend, April 5-7, 1996:4-5 (survey conducted February 1996 by ICR Research Group).

24. Ehman JW, Ott BB, Short TH, Ciampa RC, Hansen-Flaschen J. Do patients want physicians to inquire about their spiritual or religious beliefs if they become gravely ill? Arch Intern Med 1999;159:1803-1806.

25. Pargament KI, Smith BW, Koenig HG, Perez L. Patterns of positive and negative religious coping with major life stressors. Journal for the Scientific Study of Religion 1998;37:710-724.

26. Joint Commission on Accreditation of Healthcare Organizations (JCAHO). Patient rights and organization ethics. In Comprehensive Accreditation Manual for Hospitals (CAMH) : The Official Handbook (update 3). Oakbrook Terrace, Ill: JCAHO, 1999:R1-15.

27. Lo B, Quill T, Tulsky T, for the ACP-ASIM End-of-Life Care Consensus Panel. Discussing palliative care with patients. Ann Intern Med 1999;130:744749. Available at http://38.232.17.254/ethics/lo.htm (accessed July 2001).

28. Association of American Medical Colleges. Report I: Learning Objectives for Medical Student Education: Guidelines for Medical Schools. Medical School Objectives Project. Washington, DC: American Association of Medical Colleges; 1998:4. Available at http://www.aamc.org/meded/msop/report1.htm (accessed July 2001).

29. Antonovsky H, Sagy S. The development of a sense of coherence and its impact on responses to stress situations. J Soc Psychol 1986;126:213-225.

30. Association of American Medical Colleges. Report III: Contemporary Issues in Medicine: Communication in Medicine, Medical School Objectives Project. Washington, DC: Association of American Medical Colleges; 1999:25-26. Available at http://www.aamc.org/meded/msop/report3.htm\#task (accessed July 2001). 